\title{
PENGELOLAAN SAMPAH DI TPI LEKOK KABUPATEN PASURUAN TAHUN 2020
}

\author{
Rizka Firdayanti*, Darjati, Fitri Rokhmalia
}

Jurusan Kesehatan Lingkungan Poltekkes Kemenkes Surabaya

*Email korespondensi: rizkafirdayanti.rf@gmail.com

\begin{abstract}
ABSTRAK
Aktivitas penangkapan, pendaratan, pengolahan dan perdagangan ikan di TPI yang terus meningkat menghasilkan semakin banyak limbah dan sampah. Belum adanya fasilitas pengelolaan sampah khusus TPI juga menyebabkan masyarakat terbiasa membakar serta membuang sampah sembarangan. Banyaknya sampah menumpuk dan berserakan di sekitar wilayah TPI juga menimbulkan bau tidak sedap dan pencemaran lingkungan. Dampak buruk terhadap lingkungan ini menyebabkan penurunan hasil produksi ikan di TPI Lekok pada tahun 2018-2019 dari 540.283 ton menjadi 158.130 ton. Tujuan penelitian ini untuk menganalisis pengelolaan sampah di TPI Lekok Kabupaten Pasuruan. Jenis penelitian ini adalah deksriptif kualitatif dengan teknik analisis matriks SWOT untuk menentukan strategi dalam perencanaan pengelolaan sampah di TPI Lekok Kabupaten Pasuruan. Data primer diperoleh melalui observasi, pengukuran dan wawancara. Data sekunder meliputi data umum TPI, jumlah pegawai dan jumlah pedagang sebanyak 277 orang. Variabel yang diteliti yaitu volume dan komposisi sampah, faktor internal dan eksternal pengelolaan sampah serta pengelolaan sampah di TPI Lekok sesuai fungsi manajemen. Hasil penelitian menunjukkan bahwa volume sampah yang dihasilkan TPI Lekok Kabupaten Pasuruan adalah 388,49 L/hari atau 0,39 $\mathrm{m}^{3} /$ hari, dengan komposisi sampah organik lebih dominan yaitu 59,08\% dan anorganik sebesar 40,92\%. Analisis SWOT pengelolaan sampah di TPI Lekok berada di kuadran III (Turn Around) dan strategi yang diterapkan WeaknessOpportunity dengan melakukan perbaikan internal serta memanfaatkan pengelolaan sampah terpadu TPST 3R yang ada di Kecamatan Lekok. Disarankan perlu ada penambahan sarana wadah sampah terpilah untuk seluruh gedung di TPI Lekok serta melakukan pengolahan sampah dengan metode $3 R$ melalui pengomposan sampah organik dengan komposter dan daur ulang sampah anorganik plastik.
\end{abstract}

Kata Kunci : Pengelolaan Sampah, Analisis SWOT.

\section{PENDAHULUAN}

Dalam mendukung kegiatan penangkapan ikan dan peningkatan produksi perikanan tangkap di wilayah Jawa Timur Pemerintah melalui Dinas Perikanan dan Kelautan Propinsi Jawa Timur membangun prasarana perikanan berupa Pelabuhan Perikanan. Dari Laporan Tahunan KKP tahun 2017 diketahui sebanyak 333 pelabuhan dari 816 pelabuhan perikanan dinyatakan kondisinya tidak layak. Hal ini karena pelabuhan perikanan berupa bangunan terbuka, akses keluar masuk tidak terbatas, dan fasilitas yang kurang lengkap terutama pada cold storage, air bersih, IPAL, drainase dan instalasi lainnya. Salah satu sarana yang harus terdapat pada Pelabuhan Perikanan adalah Tempat Pelelangan Ikan (TPI), untuk menyelenggarakan pemasaran atau pelelangan hasil tangkapan nelayan
(Kementerian Kelautan dan Perikanan Republik Indonesia).

Aktivitas perikanan yang ada di TPI jika tidak ditunjang dengan pembangunan serta pemanfaatan sarana dan prasarana yang ada, dapat berakibat pada efisiensi / keberhasilan pelaksanaan kegiatan di TPI (Sudaryanto, 2006). Berdasarkan hasil penelitian kerja sama antar IPB dan Prancis pada rentang waktu 2000 hingga 2005 , terdapat $40 \%$ pelabuhan perikanan di Pulau Jawa yang kebersihan atau sanitasi tempat pelelangan ikannya sangat minim (Lubis, 2005). Semakin meningkatnya aktivitas penangkapan dan pendaratan ikan oleh nelayan, serta pengolahan dan perdagangan ikan oleh pedagang di TPI mengakibatkan makin banyak sampah yang dihasilkan. Hal ini tentu dapat berpengaruh terhadap 
kenyamanan dan kesehatan lingkungan masyarakat (Rahayu, 2012).

Berdasarkan hasil survey pendahuluan yang telah dilakukan, diketahui bahwa jumlah gedung di TPI Lekok Kabupaten Pasuruan berjumlah 46 buah dengan total pegawai 277 orang. Sampah yang dihasilkan dari hasil kegiatan di TPI yaitu sampah anorganik berupa kantong plastik dan kemasan makanan, untuk sampah organiknya berupa sampah hasil pengolahan ikan seperti sisik dan jeroan ikan serta sampah daun yang berasal dari pepohonan yang ada. Tidak adanya pengelolaan sampah di TPI Lekok menyebabkan banyak sampah yang berserakan di jalan dan menumpuk di sekitar wilayah TPI sehingga menimbulkan bau tidak sedap dan pencemaran lingkungan.

TPI merupakan salah satu sumber sampah dari daerah komersial sehingga diwajibkan melaksanakan pengelolaan sampah menurut Undang-undang No. 18 Tahun 2008 tentang Pengelolaan Sampah. Dalam penyediaan sarana pemilahan sampah, di TPI Lekok fasilitas tempat sampah hanya ada 16 wadah untuk 46 gedung, kondisinya tercampur dan peletakkannya hanya di sekitar kantor. Tidak ada fasilitas pengumpulan maupun pengolahan sampah skala kawasan serta pengangkutan sampah TPI Lekok yang tidak rutin ke TPA. Hal ini menyebabkan masyarakat di sekitar terbiasa membakar dan membuang sampah sembarangan ke laut atau saluran drainase, padahal perbuatan tersebut melanggar UU dan dapat dikenai sanksi hukum.

Pertambahan jumlah sampah yang tidak diimbangi dengan pengelolaan yang baik akan menyebabkan terjadinya perusakan dan pencemaran lingkungan. Dampak buruk terhadap lingkungan, juga mempengaruhi sektor kelautan. Jika dilihat dari data produksi perikanan tangkap di TPI Lekok tahun 2018-2019 mengalami penurunan hasil produksi yang signifikan, dari 540.283 ton menjadi 158.130 ton. Selain itu, kondisi pesisir pantai Lekok Pasuruan saat ini keadaannya juga sangat memprihatinkan karena dijadikan sebagai TPA sampah oleh masyarakat baik itu sampah organik maupun sampah anorganik.

Berdasarkan penelitian Krisnajayanti (2014) diketahui mayoritas masyarakat Desa Jatirejo membuang sampah tanpa membedakan jenis sampah yang dibuang. Hanya $34,78 \%$ masyarakat yang sudah bisa membedakan jenis sampah, dan sisanya 65,22\% tidak bisa. Sedangkan untuk pengelolaan/ pemusnahan sampah, sebesar $19,57 \%$ masyarakat mengetahui pengelolaan/pemusnahan sampah, dan $80,43 \%$ tidak mengetahui. Hasil penelitian ini menjukkan bahwa pengetahuan masyarakat akan jenis - jenis sampah dan pengelolaannya masih kurang. Sehingga menyebabkan banyak sampah berserakan di jalan, menumpuk di sekitar wilayah TPI serta menimbulkan bau tidak sedap.

Pengelolaan sampah adalah kegiatan yang sistematis, menyeluruh, dan berkesinambungan yaitu meliputi pengurangan dan penanganan sampah. Berdasarkan penelitian Dyah (2012) dalam pengelolaan sampah diperlukan adanya analisis kondisi internal maupun eksternal pengelolaan sampah yang meliputi aspek pengelolaan sampah mulai dari kelembagaan, peraturan, pembiayaan, teknis operasional dan partisipasi masyarakat. Dari penelitian tersebut diketahui bahwa strategi pengelolaan bertumpu pada perubahan pola pikir untuk mengelola sampah kota bersama antara pemerintah masyarakat dan swasta dengan penerapan pengurangan, pemakaian kembali, daur ulang dan pembuangan yang aman bagi lingkungan. Sehingga dapat disimpulkan bahawa dalam pengelolaan sampah tidak hanya menjadi kewajiban pemerintahsaja melainkan masyarakat diharapkan juga bisa mendukung strategi dalam mengolah sampah secara mandiri.

Menurut Winahyu (2013) dalam merumuskan kebijakan pengelolaan sampah dapat dilakukan dengan menggunakan analisis SWOT untuk memformulasikan atau mengembangkan berbagai pilihan strategi. Berdasarkan hasil analisis pada penelitian tersebut, disimpulkan bahwa optimalisasi pengelolaan TPA Bantargebang dapat dicapai melalui empat alternatif strategi, yaitu: peningkatan infrastruktur, yang 
melibatkan investor dalam pembangunan dan pengoperasian TPA, mempromosikan partisipasi sosial, dan meningkatkan kualitas sumberdaya manusia. Tujuan dari penelitian ini untuk menganalisis pengelolaan sampahdi TPI Lekok Kabupaten Pasuruan.

\section{METODE PENELITIAN}

Jenis penelitian ini deksriptif kualitatif dengan teknik analisis matriks SWOT. Objek penelitian ini adalah volume dan komposisi sampah serta pengelolaan sampah di TPI Lekok Kabupaten Pasuruan. Subjek penelitian ini adalah narasumber yang terkait dengan pengelolaan sampah di TPI Lekok Kabupaten Pasuruan. Metode yang digunakan dalam pengumpulan data adalah pengukuran, observasi, dan wawancara. Data dianalisis menggunakan matriks SWOT dan disajikan dalam bentuk tabel serta diuraikan dalam pembahasan yang dibandingkan dengan Undang-
Undang Republik IndonesiaNomor 18 Tahun 2008 tentang Pengelolaan Sampah.

\section{HASIL DAN PEMBAHASAN Volume Sampah}

Volume sampah adalah banyaknya sampah yang dihasilkan dari jenis sumber sampah di wilayah tertentu per satuan waktu. Informasi mengenai volume sampah sangat diperlukan untuk menentukan dan mendesain peralatan yang digunakan dalam transportasi sampah, fasilitas recovery material, dan fasilitas tempat pembuangan akhir (TPA) sampah.

Pengambilan data volume sampah di TPI Lekok dengan menggunakan Peraturan Menteri Pekerjaan Umum Republik Indonesia Nomor 03 Tahun 2013 yang mengacu SNI 19.3964-1994 tentang metode pengambilan dan pengukuran contoh timbulan sampah dan komposisi sampah perkotaan.

Tabel 1

Volume Sampah Tiap Sumber di TPI Lekok Kabupaten Pasuruan Tahun 2020

\begin{tabular}{cccc}
\hline No & Sumber Sampah & $\begin{array}{c}\text { Volume Sampah } \\
\text { per Orang } \\
\text { (L/org/hari) }\end{array}$ & $\begin{array}{c}\text { Volume Total } \\
\text { Sampah } \\
\text { (L/hari) }\end{array}$ \\
\hline 1. & Warung & 1,99 & 19,9 \\
\hline 2. & $\begin{array}{c}\text { Gedung } \\
\text { Pengolahan Ikan }\end{array}$ & 1,56 & 276,12 \\
\hline 3. & $\begin{array}{c}\text { Gedung } \\
\text { Pengepakan Ikan }\end{array}$ & 0,95 & 67,45 \\
\hline 4. & $\begin{array}{c}\text { Sekitar Kantor } \\
\text { Pengelola }\end{array}$ & 0,72 & 11,52 \\
\hline 5. & Penyapuan Jalan & - & 13,5 \\
\hline TOTAL & 388,49 & & \\
\hline
\end{tabular}

Sumber : Data Primer, 2020

Berdasarkan tabel tersebut diketahui bahwa volume total sampah dari seluruh unit di TPI Lekok Kabupaten Pasuruan Tahun 2020 adalah 388,49 L/hari atau $0,39 \mathrm{~m} 3 /$ hari. Peraturan khusus yang mengatur maupun menyatakan besaran angka timbulan sampah untuk TPI maupun pelabuhan perikanan belum tersedia sehingga digunakan penelitian yang hampir sama sebagai pembanding. Penelitian milik Wijaya (2014) tentang Perencanaan Pengelolaan Sampah Di Obyek Wisata Eks Pelabuhan Buleleng memberikan hasil total volume sampah setiap harinya sebesar 1,033 m3 sedangkan untuk volume sampah yang dihasilkan di TPI Lekok adalah sebesar 0,39 m3/hari, sehingga dapat disimpulkan bahwa volume sampah TPI Lekok termasuk kecil. Hal ini karena perbedaan jenis kegiatan dan jumlah orang yang ada pada kedua tempat tersebut.

Volume sampah per orang yang ada di TPI Lekok Kabupaten Pasuruan Tahun 2020, terbesar berasal dari Warung dan terkecil berasal dari unit Sekitar Kantor 
Pengelola. Sedangkan untuk volume total sampah dari tiap unit terbesar berasal dari Gedung Pengolahan Ikan dan terkecil berasal dari Gedung sekitar kantor. Pada gedung pengolahan ikan, pengepakan dan penyimpanan ikan banyak sampah tercecer dan berserakan. Sedangkan untuk wilayah sekitar kantor terlihat bersih dan rapi tidak ada sampah yang berserakan. Hal ini terjadi karena pelayanan pewadahan dan pengangkutan sampah hanya ada untuk wilayah di sekitar kantor. Sedangkan untuk tiap gedung yang disewa pengelolaan sampah dan kebersihan menjadi tanggung jawab penyewa.

\section{Komposisi Sampah Organik dan Anorganik}

Komposisi sampah merupakan penggambaran dari masing-masing komponen yang terdapat pada sampah dan didistribusinya. Data ini penting untuk mengevaluasi peralatan, sistem, pengolahan sampah, danrencana manajemen pengelolaan sampah kota. Pengelompokkan sampah yang paling sering dilakukan adalah berdasarkan komposisinya yang biasadinyatakan sebagai $\%$ berat. Komposisi sampah dapat dibedakan menjadi 2 yaitu komposisi sampah organik dan anorganik.

Tabel 2

Komposisi Sampah Tiap Sumber di TPI Lekok Kabupaten Pasuruan Tahun 2020

\begin{tabular}{lccc}
\hline \multirow{2}{*}{ No } & Sumber Sampah & \multicolumn{2}{c}{ Komposisi } \\
\cline { 3 - 4 } & & Organik & Anorganik \\
\hline 1. & Warung & $44,6 \%$ & $55,4 \%$ \\
\hline 2. & Gedung Pengolahan Ikan & $58,9 \%$ & $41,1 \%$ \\
\hline 3. & Gedung Pengepakan Ikan & $49,8 \%$ & $50,2 \%$ \\
\hline 4. & Sekitar Kantor Pengelola & $65 \%$ & $35 \%$ \\
\hline 5. & Penyapuan Jalan & $77,1 \%$ & $22,9 \%$ \\
\hline & Rata-rata & $59,08 \%$ & $40,92 \%$
\end{tabular}

Sumber : Data Primer, 2020

Dari data tersebut diketahui bahwa komposisi sampah yang dihasilkan tergantung dari kegiatan yang ada di sumber sampah berasal. Sampah organik paling banyak dihasilkan dari penyapuan jalan sekitar kantor pengelola dan tempat penjemuran ikan dengan prosentase sebesar $77,1 \%$ dan paling sedikit dari warung yaitu sebesar $44,5 \%$. Sedangkan untuk sampah anorganik paling banyak dihasilkan dari warung sebesar $55,4 \%$ dan paling sedikit sebesar $22,9 \%$ berasal dari penyapuan jalan yang lebih banyak menghasilkan sampah organik karena sampah berasal dari pohon dan tanaman yang tumbuh disepanjang jalan sekitar kantor dan tempat penjemuran ikan.

Berdasarkan tabel tersebut diketahui bahwa jenis sampah anorganik dari seluruh unit kurang lebih komposisinya sama yaitu botol plastik, kemasan plastik makanan minuman, dan kantong plastik. Sampah organik pada tiap unit berbeda antara satu dan lainnya. Seperti jenis sampah organik dari warung kebanyakan berupa sisa sayuran, kulit buah, sisa makanan, daun dan ranting. Lalu untuk jenis sampah organik dari gedung pengolahan serta pengepakan ikan yaitu berupa sisik dan jeroan ikan. Sedangkan untuk wilayah sekitar kantor didominasi sampah seperti kertas, daun dan ranting hasil penyapuan jalan sekitar kantor yang ditumbuhi banyak pohon dan tanaman.

\section{Analisis SWOT Pengelolaan Sampah}

Dalam menentukan strategi yang cocok diterapkan untuk Pengelolaan Sampah di TPI Lekok Kabupaten Pasuruan terlebih dahulu dilakukan penilaian dari sistem pengelolaan sampah yang selama ini ada disana berdasarkan formulir yang telah dibuat. Hasil penilaian tersebut selanjutnya dijadikan bahan untuk menyusun beberapa faktor strategi eksternal dan internal untuk analisis SWOT pengelolaan sampah. Informasi yang diperlukan berasal dari hasil 
wawancara terhadap stakeholder terkait pengelolaan sampah di TPI Lekok. Sehingga dari beberapa aspek wawancara yang sudah dilakukan dapat ditarik kesimpulan faktor kekuatan, kelemahan, peluang, dan ancaman.

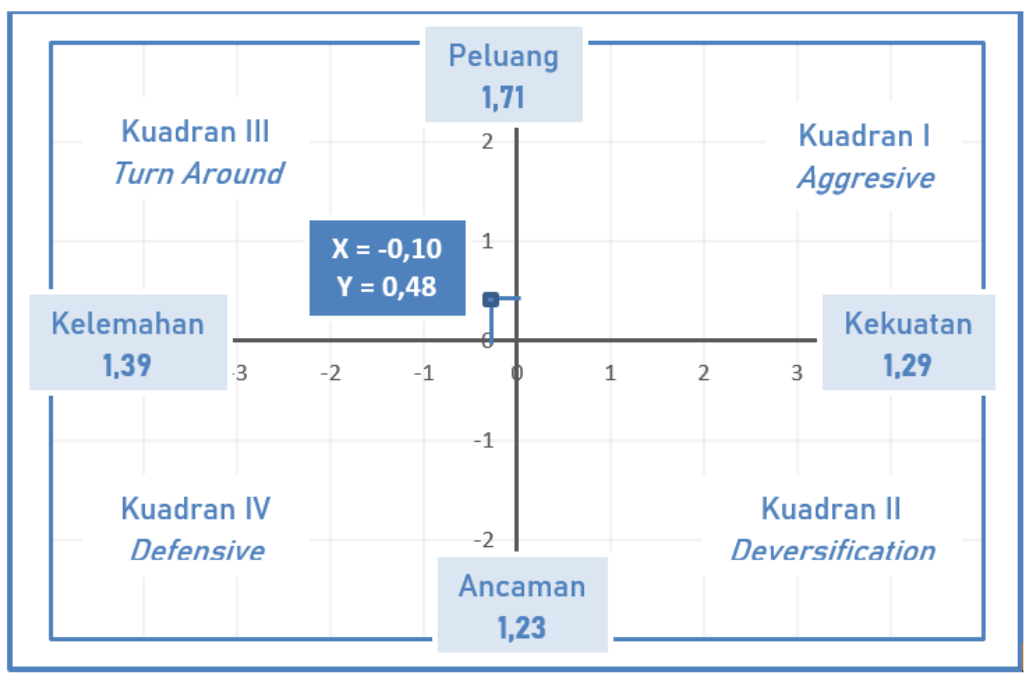

Gambar 1. Matriks Kuadran SWOT Pengelolaan Sampah TPI Lekok

Pada tahapan selanjutnya yaitu menggunakan matriks SWOT untuk menentukan alternatif strategi yang sesuai dan dapat diterapkan secara efektif. Posisi relatif didapat dengan menjumlahkan kekuatan, kelemahan, peluang dan ancaman sebagai bidang (area) kuadran SWOT. Titik $X=-0,10$ yaitu hasil selisih dari jumlah perkalian bobot dan rating pada kekuatan dan kelemahan. Titik $Y=0,48$ merupakan hasil selisih dari jumlah perkalian bobot dan rating pada peluang dan ancaman. Berdasarkan gambar diatas dapat disimpulkan bahwa hasil perhitungan matriks SWOT pengelolaan sampah TPI Lekok berada di kuadran III (Turn Around) dengan Strategi WeaknessOpportunity.

Seperti pada penelitian Winahyu (2013) setelah diketahui faktor eksternal dan internal berdasarkan hasil analisis SWOT selanjutnya dirumuskan 10 alternatif strategi dalam pengelolaan TPA Bantargebang Bekasi. Sengkan untuk hasil perumusan strategi pengelolaan sampah TPI Lekok sendiri yaitu terdapat 8 alternatif strategi WO yang dapat diterapkan. Penerapan taktik/strategi baru dalam pengelolaan sampah ini berbeda dari pengelolaan sampah yang ada sebelumnya, yaitu dilakukan melalui kerjasama dengan pengelola sampah di sekitar Lekok, memanfaatkan perkembangan IPTEK serta teknologi dalam mengolah sampah dan melakukan perbaikan pada beberapa aspek pengelolaan sampah yang selama ini belum optimal.

\section{Rencana Pengelolaan Sampah}

Pada TPI Lekok belum terdapat pengelolaan sampah sesuai dengan UU No. 18 tahun 2008 tentang Pengelolaan sampah. Oleh karena itu perlu dilakukan atau disusun suatu rencana pengelolaan sampah kawasan yang terpadu untuk kawasan TPI Lekok yang sistematis, menyeluruh dan berkesinambungan meliputi pengurangan dan penanganan sampah. Proses perencanaan diawali dengan melakukan kajian mengenai volume dan komposisi sampah di TPI Lekok sehingga dapat memperkirakan potensi sampah yang dapat dikelola di kawasan.

Konsep perencanaan pengelolaan sampah di TPI Lekok Kabupaten Pasuruan disusun sesuai dengan pendekatan manajemen melalui Perencanaan, Pengorganisasian, Pengarahan, Pengawasan, dan Evaluasi. Pada tahapan perencanaan sendiri akan mengacu pada 5 aspek pengelolaan sampah yaitu aspek 
teknik operasional (timbulan, pemilahan, pengumpulan, pengangkutan, pengolahan dan pemrosesan akhir sampah), aspek kelembagaan dan organisasi, aspek peraturan, aspek pembiayaan dan aspek peran serta masyarakat.

Jika dibandingkan dengan penelitian yang telah dilakukan Annisa (2017) dalam merencanakan Sistem Pengelolaan Sampah Terpadu di Kota Semarang melalui kegiatan pemilahan dan pengomposan di TPS 3R. Kegiatan pengolahan sampah yang akan dilakukan di TPI Lekok tidak jauh berbeda karena pengelolaan sampah dilakukan melalui pemilahan sampah disumber/tiap gedung yang ada di TPI. Hanya saja setelah pemilahan dikarenakan keterbatasan lahan sulit untuk dilakukan pembangunan TPS 3R. Sehingga nantinya sampah organik akan diolah lebih lanjut menjadi kompos melalui komposter yang diletakkan di belakang gedung pertemuan dan sampah anorganik dijual kepada pihak ketiga.

Urutan prosedur operasional pengelolaan sampah di TPI Lekok meliputi kegiatan pemilahan sampah dari sumber penghasil, pengumpulan oleh petugas, pengangkutan ke TPS, pemilahan ulang, pengolahan, dan penyetoran kepada pihak ketiga. Lalu dari segi aspek kelembagaan dan organisasi akan dilakukan bebrapa perbaikan terkait pembagian tugas pada Bagian Kebersihan secara lebih rinci dan terstruktur dalam pelaksanaan pengelolaan sampah.

Dari aspek peraturan diperlukan beberapa perbaikan dan penambahan peraturan terkait pengelolaan sampah, mulai dari tanggung jawab pengelolaan, besaran anggaran dan restribusi serta kewajiban dan sanksi yang akan diterapkan. Untuk aspek pembiayaan yang direncanakan berupa jenis-jenis pembiayaan yang diperlukan seperti biaya investasi dan opersional serta sumber pembiayaannya. Terakhir dari aspek peran serta masyarakat disusun beberapa cara pemberdayaan masyarakat dan halhal yang harus dilakukan masyarakat untuk mendukung serta turut aktif dalam pengelolaan sampah di TPI Lekok Kabupaten Pasuruan.

\section{KESIMPULAN}

1. Hasil penelitian volume sampah yang dihasilkan di TPI Lekok Kabupaten Pasuruan adalah 388,49 L/hari atau $0,39 \mathrm{~m}^{3} /$ hari..

2. Hasil penelitian komposisi sampah yang ada di TPI Lekok menunjukkan bahwa rerata prosentase komposisi sampah organik sebesar $59,08 \%$ dan sampah anorganik sebesar $40,92 \%$.

3. Hasil penelitian analisis SWOT menunjukkan posisi relatif pengelolaan sampah di TPI Lekok Kabupaten Pasuruan berada pada kuadran III yaitu (Turn Around) sehingga strategi pengembangan yang sesuai yaitu strategi Weakness-Opportunity.

4. Hasil penelitian Rencana Pengelolaan Sampah di TPI Lekok Kabupaten Pasuruan disusun sesuai dengan pendekatan manajemen dan mengacu pada 5 aspek pengelolaan sampah serta perbaikan pada beberapa aspek pengelolaan sampah lainnya.

\section{SARAN}

1. Bagi Instansi Terkait

a. Perlu dilakukan pemilahan sampah sejak di sumber, dengan penambahan sarana wadah sampah yang disesuaikan penempatannya untuk seluruh gedung yang ada di TPI Lekok.

b. Dapat melakukan pengolahan sampah organik TPI dengan komposter dan daur ulang sampah anorganik plastik.

c. Perlu dilakukan pengawasan rutin tiap bulan pada pengelolaan sampah yang dilakukan petugas dan penyewa lahan di TPI Lekok

d. Dapat memberikan sosialisasi, pemasangan poster atau pembagian leaflet terkait pentingnya dan manfaat pengelolaan sampah yang baik dan benar di wilayah TPI Lekok

2. Bagi Masyarakat
a. Agar tidak melakukan pembuangan sampah secara sembarangan ke laut maupun pembakaran sampah.
b. Melakukan pengelolaan sampah dengan metode $3 R$ dan turut aktif 
dalam mendukung pengelolaan sampah TPI.

\section{Bagi Peneliti Selanjutnya}

Dapat digunakan sebagai bahan referensi dan pertimbangan untuk penelitian dengan metode analisis yang berbeda serta pengembangan pengolahan sampah ikan yang dapat diterapkan di wilayah TPI.

\section{DAFTAR PUSTAKA}

Annisa, M.P, Priyambada, I. B, Handayani, D.S, 2017. Perencanaan Sistem Pengelolaan Sampah Terpadu (Studi Kasus Rw 09, 10, Dan 11 Kelurahan Tanjung Mas, Kecamatan Semarang Utara, Kota Semarang). Jurnal Teknik Lingkungan, Vol. 6, No. 1.

Dyah, E, Budiastuti, S, Masykuri, 2012. Analisis Komposisi, Jumlah dan Pengembangan Strategi Pengelolaan Sampah Di Wilayah Pemerintah Kota Semarang Berbasis Analisis SWOT. Jurnal EKOSAINS. Vol. IV No. 2.

Krisnajayanti, F, Zain, I.M, 2014. Kajian Permukiman Kumuh Di Kawasan Pesisir Desa Jatirejo Kecamatan Lekok Kabupaten Pasuruan. Mahasiswa S1 Pendidikan Geografi, Fakultas IImu Sosial dan Hukum, Universitas Negeri Surabaya

Laporan Tahunan Kementerian Kelautan dan Perikanan Republik Indonesia Tahun 2017.

Lubis E. 2005. Buku I: Pengantar Pelabuhan Perikanan. Bahan Kuliah Pelabuhan Perikanan. Laboratorium Pelabuhan Perikanan. Bogor: Departemen Pemanfaatan Sumberdaya Perikanan, Fakultas Perikanan dan Ilmu Kelautan, Institut Pertanian Bogor.

Peraturan Menteri Pekerjaan Umum Republik Indonesia Nomor 03
Tahun $2013 \quad$ Tentang Penyelenggaraan Prasarana Dan Sarana Persampahan Dalam Penanganan Sampah Rumah Tangga Dan Sampah Sejenis Sampah Rumah Tangga Rahayu, L, Rosyid, A, Boesono, H, 2012. Analisis Perbandingan Efisiensi Tempat Pelelangan Ikan (TPI) Tasikagung, Karanganyar, dan Sarang di Kabupaten Rembang, Journal of Fisheries Resources Utilization Management and Technology, Vol 1(1) : 77-86.

SNI 3242: 2008 Tentang Pengelolaan Sampah di Permukiman

Sudaryanto, B, 2006. Analisis Efisiensi Pengelolaan Tempat Pelelangan Ikan (TPI) dengan Data Envelopment Analysis (DEA): studi di Kabupaten Rembang dan Kabupaten Rembang Jawa Tengah. Jurnal Empirika, Vol 19(1): 35-46.

Undang-undang Republik Indonesia nomor 18 Tahun 2008 tentang Pengelolaan Sampah.

Wijaya,M.W, Trihadiningrum, Y, 2014. Perencanaan Pengelolaan Sampah Di Obyek Wisata Eks Pelabuhan Buleleng, Kabupaten Buleleng. Tugas Akhir. Program Sarjana Jurusan Teknik Lingkungan Fakultas Teknik Sipil Dan Perencanaan Institut Teknologi Sepuluh Nopember Surabaya.

Winahyu, D, Hartoyo, S, Syaukat, Y, 2013. Strategi Pengelolaan Sampah Pada Tempat Pembuangan Akhir Bantargebang, Bekasi. Jurnal Manajemen Pembangunan Daerah Vol 5, No 2.

Zain, J, Syaifudin,Y, A.H, 2011. Pelabuhan Perikanan. Pusat Pengembangan Pendidikan. Universitas Riau. Pekanbaru. Hal 176. 